defensible, and if the implications sketched here are compelling, it suggests that the categorization of theoretical perspectives into hard and soft and the characterization of nonpositivists as negativist (with its historical connotations) are misleading, are barriers to serious discussion between alternatives, and ought to be abandoned. For those terms are tied to a period when the rationality of political inquiry was considered to be less problematic and faith in the hard-positivist mode of analysis less questioned and less questionable.

The current potential for theoretical pluralism in political science holds the promise of lively debate among competing theoretical perspectives. The development of that theoretical pluralism would undoubtedly open up new terrain, generate new issues, and recast old ones. Political science would be impoverished if this potential were unintentionally shortcircuited by the adherence to a vocabulary that inaccurately predefines the issues and falsely prejudices the alternatives.

\section{Note}

1. I should point out here that postempiricism does not necessarily entail a rejec- tion of foundations per se. But most postempiricists/post-positivists have accepted post-foundationalism as well. Hence, I have focused on a version of post-empiricism/ post-positivism that does have an anti-

foundationalist thrust to it.

It should also be clear that on this reading post-positivism is incompatible with the orthodox versions of Marxism with which Almond groups it.

\section{References}

Almond, Gabriel. 1988. "Separate Tables: Schools and Sects in Political Science," PS: Political Science \& Politics, Fall 1988, Vol. XXI, No. 4, pp. 828-42.

Bernstein, Richard. 1983. Beyond Objectivism and Relativism. Philadelphia: University of Pennsylvania Press.

Comte, August. 1975. August Comte and Positivism: The Essential Writings, Gertrud Lenzer, ed. New York: Harper and Row.

Eckstein, Harry. 1971. The Evaluation of Political Performance. Beverly Hills: Sage Publications. 1989. "A Comment on Positive Theory,', PS: Political Science \& Politics, March 1989, Vol. XXII, No. 1, p. 77.

Feyerabend, Paul. 1975. Against Method. New York: New Left Books.

Foucault, Michel. 1972. "The Discourse on Language," in Foucault, The Archeology of Knowledge. New York: Harper and Row, pp. 215-37.
Hayek, F. A. 1952. The Counter-Revolution of Science. Glencoe, Ill.: The Free Press.

Hesse, Mary. 1980. Revolutions and Reconstructions in the Philosophy of Science. Brighton, England: Harvester Press.

Horkheimer, Max. 1977. Critical Theory. New York: Seabury Press.

Kuhn, Thomas. 1962. The Structure of Scientific Revolutions. Chicago: University of Chicago Press.

1977. The Essential Tension: Selected Studies in Scientific Tradition and Change. Chicago: University of Chicago Press.

Mill, John Stuart. 1961. August Comte and Positivism. Ann Arbor: University of Michigan Press.

Rorty, Richard. 1979. Philosophy and the Mirror of Nature. Princeton: Princeton University Press.

Toulmin, Stephen. 1961. Foresight and Understanding. New York: Harper and Row.

Wolin, Sheldon. 1972. "Political Theory as a Vocation," in Martin Fleisher, ed., Machiavelli and the Nature of Political Thought. New York: Atheneum Books, pp. 23-75.

\title{
Rational Choice Theories and Politics: A Research Agenda and a Moral Question
}

\author{
Jürg Steiner, University of North Carolina at Chapel Hill \\ and University of Bern
}

Recently, there has been much discussion in the profession about why rational choice theorists do what they do. Gabriel A. Almond (1988a, 835) is troubled by the way many of them preempt "the badge of professionalism and (by) their demotion of the rest of us to a prescientific status." David McKay $(1988,1054)$ wonders why there are so many rational choice theorists in the United States and not in Europe.

Authors such as Almond and McKay take the behavior of rational choice theorists as dependent variable, the phenomenon they wish to explain. In the present essay I reverse the question, making the behavior of rational choice theorists my independent variable. 1 am interested in the question of how the teaching of rational choice theories to our students influences their political views and perhaps in the long term the political culture at large. This is a special question within a much broader problem, namely how teaching political science influences the political life of a country. My general point is that we need theories to explain how the teaching of our theories affect political reality. It is not sufficient for political scientists to explain political life, we must also consider how these explanations, through our teaching, affect political life. But why focus on rational choice theories? As the essay will quickly reveal, its writing has been driven by a specific worry. But I hope that the example of rational choice theories will allow me to make a more general point.

Within rational choice theories my worry focuses on a specific subgroup whom I label, for the lack of a better term, hard-line rational choice theorists. They assume that voters and 
politicians are utility maximizers in a very narrow sense and, directly or indirectly, imply that this assumption is descriptively accurate and even normatively appropriate. Voters, in choosing among candidates, look in an egotistical way for their material self-interest. Politicians, equally selfishly, are motivated to be elected and reelected. Rational choice theories may be based on other motives including motives of morality and altruism. The assumption may also be made as a purely heuristic device to simplify the initial formulation of a problem. In these cases I am not worried about the consequences of teaching rational choice theories. My concern focuses on theories which are based on the axiom of a narrowly conceived and materially oriented egoism, especially if in the course of one's research this axiom is never seriously challenged. Almond (1988b) calls this "core" rational choice theory; in my view, "hard-line" rational choice theory may give a more appropriate connotation. For an entire generation of hard-line rational choice theorists William $\mathrm{H}$. Riker $(1962,22)$ has formulated the basic axiom in a very concise way: "Politically rational man is the man who would rather win than lose, regardless of the particular stakes." Thus, winning is always better than losing; staying in office better than being thrown out of office; a higher office better than a lower one. Looking through the current journals it is not difficult to identify articles by rational choice theorists who work with the assumption that politicians maximize their election chances. A typical example is an article by David Austen-Smith and Jeffrey Banks in the June 1988 issue of the American Political Science Review where the authors build a model based on the axiom that "rational candidates" select "their electoral strategy and subsequent legislative behavior conditional on electoral success" (AustenSmith and Banks, 1988, 405). Thus winning seems to be everything. Legislative behavior is oriented towards future elections.

If we teach our students that this is the premise which allows us best to explain the behavior of politicians, some of our most sensitive students may be shocked and repulsed by this view of politics as an essentially selfish enterprise. They may deny that this accurately describes the world in which we live. But many students, impressed by the professional authority of their teachers, will blindly accept the explanation. For these students it is then a small step to confound explanation with justification. What can be explained, must somehow also be justified. If, indeed, the premise that politicians are primarily motivated in gaining and keeping political office corresponds to some kind of natural law, then one has to accept and live with this state of nature.

Whether these speculations about the consequences of teaching hard-

\section{It is puzzling that we as}

a profession hardly ever study the effect of our teaching on our students and through them on the political life of the country at large.

line rational choice theories actually correspond to reality, is in principle open to empirical research. It is puzzling that we as a profession hardly ever study the effect of our teaching on our students and through them on the political life of the country at large. In trying to explain political life, political scientists touch on virtually all aspects of society, not only on the polity, but also on what happens in families, schools, churches, the media, the work place, during leisure time, etc. What we strangely ignore is what happens in political science itself. Do we not expect that our teaching will in some way shape the political views of our students in later life? Will it not make a difference for the political orientation of our students whether we teach them Immanuel Kant, Jürgen Habermas or rational choice theory? Are we not aware that we are not only observers but, through our research and teaching, also actors in the political life of a country? This essay wishes to remind us that we have not only professional but also political responsibilities. If we undertake a major reorientation in our profession, we should also consider its political implications. And the emergence of rational choice theories in the last ten to twenty years is indeed a major reorientation of our discipline. If we assume that in an ultimate sense political science should help to improve political life (e.g., Huntington, 1988), then, of course, we should be interested in the political implications of such a reorientation in our profession. This, of course, should be true for any reorientation. Thus, when in the 1960s many American political scientists turned to a structural-functionalist approach, the political implications of this reorientation should also have been considered, which they were not.

To consider the political implications of one's research and teaching is important for any academic discipline, and many such as biology and physics do indeed make such efforts. Why not political science? Quite ironically, it seems that with our research tools we should be the discipline best equipped to investigate the political implications of our research and teaching activities. In this essay, I wish to describe to what specific research agenda such an inquiry may lead and what moral questions we will have to confront.

A first empirically testable hypothesis was already mentioned, namely that the explanations of hard-line rational choice theories tend to be perceived by students not merely as explanations but also as justifications. As Murray Edelman (1988, 1337) argues, "(i)f language is a political weapon, the language of social science has proven an especially effective one and never more so than when it claimed to be professional, analytic, and scientific." To study whether the highly formalized language of hard-line rational choice theories has also a normative effect on the students exposed to these theories, standard research techniques can be used. One would have to compare student classes where hard-line rational choice theories are taught with control groups without any exposure to these theories. There is already an interesting research 
finding relevant in this context. Experiments conducted by Gerald Marwell and Ruth Ames (1981) revealed that graduate students in economics free ride more often than other students. Could the reason be that the theories taught in economics are so much based on material self interest?

In longitudinal studies one would have to investigate to what extent the differences that are found endure or dissipate over time. It would be particularly important to pursue students who later become journalists because they have to interpret politics for the general public. Do journalists trained in hard-line rational choice theories interpret the news differently from their colleagues without such training? Let us take as an illustration reporting about the problem of the homeless. Journalists who had their training not in hard-line rational choice theories but, for example, in Kantian philosophy could be expected to interpret the problem of the homeless in terms of the duties of society. Those with Marxist training would tend to interpret the problem in terms of class struggle. How about journalists with a thorough training in hard-line rational choice theories? I hypothesize that they would primarily ask whether tackling or not tackling the problem of the homeless is likely to affect the election chances of various groups of politicians. Interpreting the news in this framework would help to reinforce the perceptions of politics held by readers and voters trained in hard-line rational choice theories. Such journalists would help these voters to maintain the views learned way back in their political science classes. As a real-life illustration which nicely fits in this context, I wish to mention the four-hour-long television show "The Power Game," narrated by Hedrick Smith and aired by PBS January 2-5, 1989. This show made in a powerful way and with sophisticated tools the point that in the power game in Washington winning is everything.

How would politicians behave in an environment dominated by journalists and voters trained in hard-line rational choice theories, especially if they themselves had training in these theories? Three aspects come to mind concerning the time perspective of their decisions, the voters they consider in their decisions, and the programs they favor. (1) Politicians would have a relatively short time perspective because the next election is always just around the corner. If the issue were, for example, to reduce the parking space in a city so that in the long-term interest of the environment private traffic would be discouraged, these politicians would hardly be in favor of the policy. The benefits of such a measure would lie far in the future and it would also be unclear from which voters exactly, if any, these politicians could ever expect any rewards. On the other hand, quick punishment in the next election from automobile lobbies would be virtually certain. We must also consider that voters would expect that their individualistic self interests be fulfilled by politicians. The voters would ask how they profit if they vote for a particular politician. Arguments involving duty for the well-being of future generations would find little fertile ground among politicians and voters alike. The logic of the situation would be for politicians to do what pays off best at the next election, because according to the teaching of hard-line rational choice theories winning is always better than losing. Everything else would appear as irrational, a point explicitly made by Riker (1962, 22) who states: "Unquestionably there are guilt-ridden and shameconscious men who do not desire to win, who in fact desire to lose. These are the irrational ones of politics."

The time horizon of politicians can be somewhat expanded if the axiom of rational choice theorists is not merely a win in the next election but as many electoral wins as possible. Under this assumption it may be rational to risk a loss in the election immediately ahead if this could increase the electoral chances in later elections. This added sophistication helps with some of the problems of a short time perspective, but winning still remains everything, although in a longer time perspective. But even with this approach the problem of a really long time perspective beyond the political careers of current politicians is not addressed. And many issues, such as the environment and social security, must be seen in these long time perspectives.

(2) I would also expect that the needs of small unorganized groups with limited financial resources would hardly be considered because they cannot deliver anything worthwhile for elections. This need not be the case in all environments. Take the example of Swiss mountain farmers who are few in number, not particularly well organized, and certainly without large financial resources. Yet, their needs are usually quite well taken care of in the Swiss parliament where programs are often passed because they benefit a weak or marginal group (Steiner, 1974). Arguments rooted in duty and altruism are effectively brought into play in such situations. I do not wish to argue, of course, that mountain farmers are treated quite generously in Swiss politics because hard-line rational choice theories are hardly taught at Swiss universities. Causality is rather the other way around: Given the significantly less individualistic and more communal culture of Swiss society, its universities are not receptive to the introduction of courses in hard-line rational choice theories. But if the teaching of these theories were to spread in the future, electorally ineffective groups would be more hard pressed in Swiss politics. Purely electoral considerations would become stronger compared with motives of communal solidarity.

(3) Still another consequence could be that political programs would greatly emphasize tangible over intangible goods. Being accustomed to cost-benefit analyses directing their behavior, both politicians and voters would prefer that the goods delivered by the government be expressed in numerical terms because this makes them more easily comparable: so much cash subsidies for this group, so many miles of new roads for this other group. Closing a street in the inner city for private cars, on the other hand, would have little attraction because the pleasure of pedestrians to stroll leisurely along the entire street can be expressed in numerical terms only with great difficulties, if at all.

In summary, I expect that in an environment dominated by hard-line rational choice theories political deci- 
sions would tend to be made with a short time perspective, to neglect electorally ineffective voters, and to place greater emphasis on tangible rather than on intangible policy programs. How can these hypotheses be tested? The task is more difficult than with the hypotheses discussed earlier which involve individual students and journalists as units of analysis. Here the units of analysis are decision cases. One way to proceed would be to distinguish for each decision case whether and to what extent the participating actors had any training in hard-line rational choice theories. One could then investigate whether this variation had any influence on the characteristics of the decision process and its outcome (for an approach using decision cases as units of analysis see Dorff and Steiner, 1987).

If political scientists wish to systematically study the political implications of the reorientation of their discipline towards hard-line rational choice theories, this would mean a major research endeavor. This essay is a plea to the profession to engage in such research. If we believe that our research and teaching has any political relevance, then we should be concerned with precisely what this relevance is. If we undertake a major intellectual reorientation we should carefully consider the possible impact of such a reorientation on the political life of the country. More generally speaking, we have an obligation to consider the consequences of whatever we teach students in political science classes. In this essay I focus on hard-line rational choice theories, but in principle the arguments would apply to any subfield of the discipline. Thus, we should be concerned, for example, how psychologically and sociologically based voting studies affect our students, especially if they go into careers such as campaign managing, polling, political advertisement. To what extent will they use the acquired knowledge to manipulate voters and thus to hurt the democratic quality of the country?

With regard to the reorientation towards hard-line rational choice theories, the debate can and should begin even before the research agenda outlined in this paper is implemented. For the time being, the basis can be educated guesses which later can be based on firmer ground as research results come in.

To get the discussion rolling, and assuming that the hypotheses presented in this essay are not completely off the mark, I venture to express the opinion that the widespread teaching of hard-line rational choice theories may have negative consequences for American society if this teaching is not embedded in a broader philosophical framework. This opinion is, of course, anchored in a particular value premise, namely that in American society the individualistic pursuit of material goods has been taken to an unhealthy extreme. There is too much emphasis on the question: "What is in it for me?" There is too much emphasis on winning, to be number one, to kill the other guy, at least in a figurative sense. Americans learn as early as in little league football that winning is everything, that, cheered on by their parents, they have to go for the kill. Later on, they encounter the same expectation everywhere in society: in the business world, in politics, and even in academia. What touchdowns were in little league football, profits become in the business world, political offices in politics, publications and citations in academia. The name of the game is to accumulate as many of these trophies as possible. This is closely related to the strange American fascination with statistics of comparative standing: Who is in the top ten percent of the class? Who is the top coach in the country, the top governor, the teacher of the year?

There are costs to this extreme competitiveness, such as stressinduced mental and physical illnesses, perhaps corruption, perhaps an aggressive foreign policy. The teaching of hard-line rational choice theories may further reinforce the competitive nature of American society. Many of my colleagues see nothing wrong with this. For them competition is the core of human nature, and therefore, the more of it the better. According to this view competition is the essential pleasure of life. Many Americans are dismayed to hear that in a country like Switzerland business cartels are legal and all major parties share power in the executive cabinet. If one is accustomed to competition, such a culture may appear dull and stifling, and to a certain extent it is.

My point is certainly not that the teaching of hard-line rational choice theories should be reduced. But as teachers we should be much more aware of the political implications of this teaching, and for that matter, of any teaching. Political implications are much less apparent if an approach to knowledge helps to reinforce the status quo, but there are political implications nevertheless. When hard-line rational choice theories are taught, students should be told in a very explicit way that these theories may explain how many current politicians behave but not necessarily how they should behave. If they were taught in such a normative context, I have no objection at all against the teaching of hard-line rational choice theories. On the contrary, such teaching may allow the students to begin to reflect how important a value competition really is in their society and whether winning should be indeed everything in politics. They will be led to ponder the moral question whether someone like William A. Galston (1988, 1281, 1284 ) is right when he postulates virtues that "are not reducible to selfinterest" and rejects "any comprehensive egoism." For Galston, liberal citizenship is not "simply the pursuit of self-interest." Politicians are warned not to pursue winning at any price and "to resist the temptation to earn popularity by pandering to immoderate public demands.",

I wish to end with Amitai Etzioni (1989) who complains exactly along the line of the present paper that "through textbooks, neoclassicists teach millions of high-school and college students every year a model that, as the economist Robert Solow puts it, "underplays the significance of ethical judgments.',

\section{References}

Almond, Gabriel A. 1988a. Separate Tables: Schools and Sects in Political Science. PS: Political Science \& Politics 21: 828-42.

Almond, Gabriel A. 1988b. Rational Choice Theory and the Social Sciences. Paper presented at the Conference Honoring the 
30th Anniversary of Anthony Downs' Economic Theory of Democracy, University of California, Irvine, October 27-28, 1988.

Austen-Smith, David and Jeffrey Banks. 1988. Elections, Coalitions, and Legislative Outcomes. American Political Science Review 82: 405-22.

Dorff, Robert H. and Jürg Steiner. 1987. Decision Cases in Western Democracies: A Data Bank. Comparative Political Studies 20: 160-73.

Edelman, Murray. 1988. Skeptical Studies of Language, the Media, and Mass Culture. American Political Science Review 82: 1333-39.

Etzioni, Amitai. 1989. The 'Me First' Model in the Social Sciences Is Too Narrow. The Chronicle of Higher Education 35 (February 1): p. 44

Galston, William A. 1988. Liberal Virtues. American Political Science Review 82: 1277-90.
Huntington, Samuel P. 1988. One Soul at a Time: Political Science and Political Reform. American Political Science Review 82: 3-10.

Marwell, Gerald and Ruth Ames. 1981. Economists Free Ride. Does Anyone Else? Experiments in the Provision of Public Goods. Journal of Public Economics 15: 295-310.

McKay, David. 1988. Why Is There a European Political Science? PS: Political Science \& Politics 21: 1051-55.

Riker, William H. 1962. The Theory of Political Coalitions. New Haven: Yale University Press.

Steiner, Jürg. 1974. Amicable Agreement Versus Majority Rule. Conflict Resolution in Switzerland. Chapel Hill: University of North Carolina Press.

\begin{abstract}
About the Author
Jürg Steiner

Jürg Steiner is professor of political science at the University of North Carolina; he also has an appointment at the University of Bern. He is the author of Amicable Agreement Versus

Majority Rule (1974), European Democracies (1986), and co-author with Robert H. Dorff of $A$ Theory of Political Decision Modes (1980).
\end{abstract}

\title{
Political Science and the 21st Century: From Government to Governance
}

\author{
William W. Boyer, University of Delaware
}

\begin{abstract}
Years ago when I was teaching at Kansas State University, a Professor of Horticulture confronted me with the question: "You say you are a political scientist. . . tell me, what is scientific about politics?" I retorted: "Well, what is cultural about horticulture?"'
\end{abstract}

\section{What Is Political Science?}

This exchange did provoke me to give much more thought to what is political science. Stuart Chase has stated that the test of a scientist is the ability to predict with accuracy (Chase, 1948: ch. 17). Surely, by this standard, political science is not very scientific. And there is a lack of general agreement as to the scope of our discipline. ${ }^{1}$

Nevertheless, there is one fundamental concept I believe that does serve to give some unity to political science, and that is the concept of "power" (Robson, 1954: 17). So, when I am asked what is political science, I say that it is above all the study of "power" in society. Then, I proceed to define power as the capacity to allocate resources. I explain that political scientists are interested in all questions relating to power: who has power, how power is acquired, how it is exercised, how it is transferred, how it is lost, etc.- - or who gets what, when and how. Then I say that political scientists are interested in the study of any institution in society that exercises power: the school, church, labor union, business, government.

I then elaborate: of all institutions that allocate resources-or have power-we are interested primarily in government, ${ }^{2}$ because government is the most powerful and coercive institution in society. And since government organizes the nation-state, we also study the nation-state as the context in which government exists. And we therefore also study the relations between and among nationstates (and particularly their governments) and this we call international relations.

I suspect few political scientists would disagree with this logic. It is my contention, however, that this conception of political science is becoming obsolete and will no longer serve us as well as we enter the last decade of the 20th century and prepare our students for the $21 \mathrm{st}$ century.

\section{Momentous World Change}

Although social scientists need to rethink the concept of power (Boulding, 1989), we political scientists need not abandon our concern with this concept as providing the central unity of our discipline. I do argue, however, that governments of, within, and between nation-states should no longer command such an exclusive hold on our attention. We need to shift more attention from government to governance. Why governance? Let me explain.

We humans are in the midst of momentous world change wrought by revolutionary advances in science and technology. Ours is a time of "macrotransition," but, whatever label we affix to it, accelerating world change has created an interdependent global environment, a fragile, vulnerable global system, of which all of us are a part (Cleveland, 1980; Boyer, 1986).

Ours is a time of: a world teetering on the brink of ecological disaster; the persistence of mass poverty and hunger; the depletion of nonrenewable fuel and energy; death control surpassing birth control; exploding populations and scarce resources; oil 